\title{
AMBIENTES VIRTUAIS DE APRENDIZAGEM E SUA COLABORAÇÃO PARA O DESENVOLVIMENTO DA EDUCAÇÃO A DISTÂNCIA NO BRASIL
}

\section{ARTIGO ORIGINAL}

IZOTON, Clayton Augusto Fontana ${ }^{1}$

SANTOS, Douglas Manoel Antonio de Abreu Pestana dos ${ }^{2}$

1 Mestrado em andamento em Educação. Especialização em Psicologia Social. Especialização em Coordenação Pedagógica e Supervisão Escolar. Especialização em Psicologia Clínica. Especialização em Psicologia Jurídica e Avaliação Psicológica. Especialização em Psicanálise. Especialização em EaD e Novas Tecnologias. Especialização em MBA em Coaching e Gestão por Competência. Especialização em MBA em Desenvolvimento de Pessoas. Especialização em Comunicação Educacional e Empresarial. Especialização em Pedagogia Empresarial e Educação Corporativa. Especialização em Tecnologias e Educação a Distância. Especialização em Gestão com Pessoas. Especialização em Metodologia do Ensino Superior. Graduação em andamento em Psicologia. Graduação em Licenciatura em Pedagogia. Graduação em Bacharel em Administração. Graduação em Licenciatura em Sociologia. Graduação em Licenciatura em Filosofia. Graduação em Licenciatura em Administração. Graduação em Gestão de Recursos Humanos.

2 Orientador. Doutorado em Ciências da Educação. Mestrado em andamento em Educação. Especialização em andamento em Neurociência e Psicologia. Especialização em andamento em EAD- Ensino a distância. Especialização em Neuropsicopedagogia. Aperfeiçoamento em violência doméstica e familiar ação Atuação Criminal E Preventiva. Aperfeiçoamento em Segurança Pública e atenção às vítimas de crimes. Aperfeiçoamento em Atenção à Saúde no Sistema Prisional. Aperfeiçoamento em Gestão Educacional. Aperfeiçoamento em Educação e pobreza.

Disponível em: https://www.nucleodoconhecimento.com.br/educacao/desenvolvimento-daeducacao 
DIEHL, Marcio Cézar ${ }^{3}$

IZOTON, Clayton Augusto Fontana. SANTOS, Douglas Manoel Antonio de Abreu Pestana dos. DIEHL, Marcio Cézar. Ambientes virtuais de aprendizagem e sua colaboração para o desenvolvimento da Educação a Distância no Brasil. Revista Científica Multidisciplinar Núcleo do Conhecimento. Ano 05, Ed. 12, Vol. 08, pp. 153172. Dezembro de 2020. ISSN: 2448-0959, Link de acesso: https://www.nucleodoconhecimento.com.br/educacao/desenvolvimento-da$\underline{\text { educacao }}$

\section{RESUMO}

A educação a distância é um termo que vem se desenvolvendo há muitos anos, mas só alcançou grandes dimensões no começo do século XX, principalmente, com o uso das tecnologias de informação e comunicação online. Por meio de pesquisa bibliográfica pretende-se apresentar o avanço da educação a distância no mundo e no Brasil, descrever a evolução, mostrando que começou pela troca de correspondências até chegar ao uso da internet, com interação síncrona ou assíncrona, verificar a plataforma mais utilizada para EaD, demonstrar o aumento do número de pessoas matriculadas nesta modalidade de ensino além das principais tendências que os autores esperam para os próximos anos. A EaD tem grandes

Aperfeiçoamento em Gestão em Educação Escolar. Aperfeiçoamento em Neuropedagogia. Aperfeiçoamento em Qualificação Profissional em Abordagem Familiar Na Atenção Domiciliar. Aperfeiçoamento em Saúde da Pessoa Idosa. Graduação em Pedagogia.

3 Orientador. Doutorado Em Ciências Da Educação. Mestrado em Mídia e Conhecimento. Especialização em andamento em Saúde Pública. Pós-graduação em educação matemática. Especialização em Informática Tecnologias da Computação. Graduação em Programa Especial De Formação Pedagógica Para Docentes Da Educação Profissi. Graduação em Matemática. Graduação em Processamento de Dados. 
chances de ganhar aceitação no meio acadêmico, contudo é necessário que as pessoas saibam trabalhar com as tecnologias envolvidas no processo, ou seja, façam parte da inclusão digital, e que tanto as instituições como o Estado forneçam incentivos culturais e financeiros para essa alternativa de transmissão do conhecimento, pois somente desta forma conseguiremos atingir o objetivo da educação, que é eliminar a exclusão social das pessoas.

Palavras-chave: educação a distância, tecnologias online, tendências.

\section{INTRODUÇÃO}

Este artigo busca apresentar como os Ambientes Virtuais de Aprendizagem podem contribuir para facilitar o acesso e expansão da educação a distância. A intenção com este trabalho não é dizer se o ensino presencial ou o ensino a distância é melhor, mas mostrar como o ensino a distância pode ajudar a disseminar a educação no Brasil, principalmente usando dos meios eletrônicos de aprendizagem.

Por meio de pesquisa bibliográfica, pretende-se demonstrar como a educação a distância vem ganhando espaço, mudando a visão preconceituosa que algumas pessoas ainda têm em relação a esta modalidade de ensino, pois estamos acostumados com um sistema centrado no professor onde os alunos entram na sala de aula e absorve passivamente o que é falado, como uma verdade absoluta e, com a EaD o aluno passa a ter uma interação maior, a transmissão do conhecimento deixa de ser por uma única via e passar a ser dos professores para os alunos, alunos para professores ou ainda alunos para alunos.

O presente artigo está estruturado na primeira parte abordando brevemente o histórico da educação a distância no mundo e no Brasil. Em um segundo momento será abordado de forma geral as tecnologias educacionais online na educação a distância, detalhando as ferramentas de informação e comunicação mais comuns e os principais Ambientes Virtuais de Aprendizagem disponíveis no mercado, e por fim, quais são as principais tendências para a $\mathrm{EaD}$ no Brasil, fazendo um comparativo com os 
levantamentos mais recentes feitos por instituições especialistas em educação a distância.

\section{O SURGIMENTO DA EDUCAÇÃO A DISTÂNCIA}

A educação a distância $(\mathrm{EaD})$ não é um termo relativamente atual, porém somente agora no final do século XX e inicio do século XXI é que essa modalidade de ensino vem ganhando popularidade e aceitação entre as pessoas.

Para iniciar o entendimento a cerca do assunto, primeiramente é necessário entender qual o conceito de EaD, portanto, de acordo com Moore e Kearsley (2007) a educação a distância é um aprendizado que é planejado e ocorre normalmente com professores e alunos separados no tempo e local, exigindo técnicas especiais de comunicação por meio de diversas tecnologias.

De acordo com Martins (2005) e Nunes (2009) os primeiros registros que se tem sobre a educação a distância foram aulas por correspondências, de Cauleb Philips em março de 1728, pois a pessoa não precisava viver em Boston para estudar taquigrafia. Depois vieram outros professores com outros cursos por correspondência, e hoje, há vários países em vários continentes que possuem a EaD em todos os níveis de ensino formal ou informal.

A informação descrita acima é a mais comum dentre os autores, apontando o início da EAD no século XVIII, pois é o que se tem de registro oficialmente como tentativa de transmitir o conhecimento. No entanto, alguns autores afirmam outras teorias sobre o seu início, apontando até mesmo os tempos bíblicos.

Segundo Peters (2003, p.29):

Estou me referindo aqui a São Paulo, que escreveu suas famosas epistolas a fim de ensinar as comunidades cristãs da Ásia Menor como viver como cristãs em um ambiente desfavorável. Ele usou as tecnologias da escrita e dos meios de transporte a fim de fazer seu trabalho missionário sem ser forçado a viajar. Isso já era claramente uma

Disponível em: https://www.nucleodoconhecimento.com.br/educacao/desenvolvimento-da- 
substituição da pregação e do ensino face a face por pregação e ensino assíncronos e mediados (PETERS, 2003, p. 29).

Desta maneira fica evidente que a preocupação em transmitir o conhecimento de um lugar para o outro sem que as pessoas envolvidas nesta aprendizagem estejam no mesmo local e ao mesmo tempo é um pensamento muito antigo, e que a humanidade a cada dia vem conseguindo formas de explorar a EaD para disseminar o conhecimento.

No Brasil, a educação a distância vem ganhando espaço e buscando sempre melhorias na forma de transmitir as informações, ela vem incorporando tecnologia para levar e espalhar o conhecimento da melhor forma possível.

Em nosso país essa modalidade de aprendizado surgiu pouco antes de 1900, quando era possível encontrar anúncio de cursos profissionalizantes por correspondência circulando nos jornais do Rio de Janeiro. Esta estrutura foi melhor consolidada quando se instalaram as Escolas Internacionais em 1904, onde os cursos eram voltados às pessoas que buscavam empregos no comércio e serviços (ALVES, 2009).

De outro modo, Lopes e Faria (2013) apontam como início da EaD no Brasil a fundação da Rádio Sociedade do Rio de Janeiro no início do século XX e, a partir de então, essa modalidade de ensino foi se espalhando e aperfeiçoando no decorrer dos anos.

Alguns autores compartilham o pensamento de que a EaD chegou ao Brasil por meio do ensino por correspondência, como aconteceu em boa parte do mundo, contudo outros autores afirmam que a EaD já chegou mais avançada e ganhou ainda mais força com o surgimento de uma rádio voltada especialmente para este fim.

A EaD evoluiu e surgiram outras formas de transmitir o aprendizado, novas plataformas, recursos tecnológicos e software. Desta maneira, Maia (2002) aponta que os primeiros ambientes virtuais de aprendizagem surgiram isoladamente dentro das instituições, apresentando cursos em páginas da web, onde predominava os textos sem imagens e com o mínimo de interação.

Disponível em: https://www.nucleodoconhecimento.com.br/educacao/desenvolvimento-da- 
Porter (1997, apud Penterich, 2009) afirma que com o passar dos anos e o desenvolvimento de ferramentas de comunicação os professores começaram a usar tais ferramentas isoladamente para disponibilizar conteúdo aos alunos e a junção dos recursos de interação, as páginas com conteúdos e informações dos professores e alunos fez desenvolver o conceito que hoje chamamos de Learning Management System (LMS), ou sistema de gerenciadores de conteúdo e aprendizagem.

Assim, é possível constatar como a EaD evoluiu muito com o passar dos anos, incorporando recursos tecnológicos cada vez melhores para possibilitar o aprendizado, e essa transformação possivelmente continuará, pois a cada ano vemos novos recursos sendo desenvolvidos.

\section{O USO DAS TECNOLOGIAS NA EDUCAÇÃO A DISTÂNCIA}

Existem diversas maneiras de aprender e ensinar a distância, desde a troca de informações por cartas até o uso de computadores com acesso a internet e transmissão de áudio e vídeo.

De acordo com Moore e Kearsley (2008) as tecnologias começaram a ser utilizadas na educação a distância no inicio do século XX, com uma diferença de uma década entre o surgimento do radio e o da televisão na educação. Quando o rádio surgiu criouse muita expectativa em torno desta tecnologia, contudo não tão promissor quanto a televisão, pois as emissoras de rádio estavam mais preocupadas em anúncios comerciais.

Com o passar dos anos a EaD se desenvolveu e surgiram outros meios de transmitir o aprendizado. O seu estopim foi a junção da internet com a educação que possibilitou uma mudança na metodologia dos cursos, dando aos alunos oportunidade de aprendizado independente da hora e do lugar em que estivessem ajudando a encurtar o distanciamento que existia entre aquele que ensinava e o aluno. $\mathrm{O}$ inicio do uso da internet para a educação a distância se deu a partir do ano de 1994, quando as instituições começaram a pesquisar as potencialidades vindas dela. Com o passar dos 
anos surgiram os ambientes virtuais de aprendizagem e foram cada vez mais aperfeiçoando as formas de ensino online (MAIA; MATTAR, 2007).

A internet é uma ferramenta muito importante para a EaD e hoje está acessível a muitas pessoas. Com ela foi possível mudar a interação dos envolvidos no processo de aprendizagem, criando novas formas de se comunicar, uma vez que na EaD o foco não está no professor, mas sim nos alunos que estão interagindo e buscando conhecimento a todo o momento.

De acordo com Munhoz (2011) o aluno que opta por estudar a distância precisa ter disciplina, saber como estudar online, ter um planejamento do tempo, escolher quando e onde estudar e identificar o seu progresso de aprendizagem. A educação a distância faz com que os alunos sejam mais críticos, que busquem o aprendizado e compartilhe as ideias, o professor neste ambiente é um moderador, ele apenas faz a mediação, orientando o aluno a como alcançar o conhecimento sobre determinado tema.

$\mathrm{Na}$ EaD os alunos precisam se acostumar com a nova abordagem, precisam se desenvolver, pois trazem para si responsabilidades que antes era dos professores. Os alunos têm que ser ativos interpretando e refletindo criticamente o que estão aprendendo (PETERS, 2003).

Como não há o contato presencialmente no ensino a distância, os alunos precisam saber lidar com essa flexibilidade, aprender a aprender no ambiente virtual, dedicar uma rotina aos estudos para que possam identificar o seu progresso e entender 0 funcionamento desta modalidade de ensino. Eles precisam saber quais as tecnologias disponíveis, principalmente referentes à comunicação, pois desta forma conseguirão ficar mais próximos à instituição.

De acordo com Guarezi e Matos (2009) e Mattar (2009) o processo de comunicação na EaD pode ser síncrono ou assíncrono, pois como alunos e professores não estão juntos no mesmo espaço físico é necessário criar meios de interação entre eles, sabendo utilizar essas tecnologias, combinando-as para ter o melhor retorno possível. Alguns exemplos dos meios de comunicação síncronos são chats, videoconferências, 
audioconferências e telefone. Já os meios assíncronos são possíveis apontar a correspondência postal ou eletrônica, fóruns de discussões, etc.

O interessante no ensino a distância é que por meio de um único equipamento, no caso o computador, associado ao uso da internet, reúne um conjunto de ferramentas que incluem áudio, vídeo e textos. Além disso, está presente no mundo todo e utiliza meios síncronos e assíncronos ao mesmo tempo melhor do que qualquer outra mídia, basta que para isso as instituições saibam montar canais de comunicação com os alunos de forma assertiva.

Munhoz (2011) afirma que não podemos deixar de considerar os benefícios que a tecnologia pode trazer para os processos de aprendizagem, além disso, o avanço da tecnologia contribui para importantes mudanças sociais. Com este modelo de ensino o estudante precisa buscar as informações, envolvendo tarefas que necessitam ser desenvolvidas em grupos espalhando o conhecimento.

Deitel, Deitel e Steinbuhler (2004, p. 269) dizem que a educação a distância online também é chamada e-learning, que são "o uso da internet e de tecnologias relacionadas ao desenvolvimento, distribuição e aprimoramento dos recursos de aprendizado e apresenta um enorme potencial como um novo meio para a educação“.

O termo e-learning é uma nomenclatura na língua inglesa para descrever o uso de meios eletrônicos para a educação e, nos últimos anos vem ganhando maior relação com as tecnologias usadas por meio da internet. É importante ao menos citá-lo, uma vez que alguns autores abordam este termo desta forma, porém o mais relevante é que independente da língua utilizada para descrever essa relação a internet ajudou impulsionar o avanço dessa modalidade de ensino e aumentar a interação entre alunos e professores.

De acordo com Rosenberg (2002) o e-learning é um termo referente a utilização de tecnologias da internet para fornecer soluções a fim de melhorar o conhecimento e o desempenho. Como ele é transmitido em rede torna-se possível a atualização, armazenamento, recuperação, distribuição e compartilhamento instantâneos de

Disponível em: https://www.nucleodoconhecimento.com.br/educacao/desenvolvimento-da- 
informação, além disso, é acessível, pois utiliza a tecnologia padrão da internet criando uma plataforma de fornecimento universal.

Segundo Lazilha (2011) não apenas o meio acadêmico se beneficia com a educação a distância e o uso dos ambientes virtuais de aprendizagem, como também o meio corporativo. Esse pensamento também é compartilhado com outros autores conforme segue:

O e-learning reduz o tempo gastos e as despesas de viagens, especialmente relacionado ao treinamento corporativo, visto que frequentemente requer o deslocamento do aluno para outro local por um determinado período de tempo e permite que alunos e funcionários aprendam com os melhores professores (DEITEL; DEITEL; STEINBUHLER, 2004).

Com a utilização das tecnologias educacionais na educação a distância podem-se observar novas práticas de interação entre os alunos, professores e o conhecimento ultrapassando os limites antes enfrentados. É possível criar relações extraclasses acessando diversas informações pertinentes ao aprendizado como bibliotecas virtuais e digitais (BERTONCELLO, 2011).

É evidente como o uso da tecnologia pode expandir o conhecimento, pois professor e alunos não estão mais limitados ao espaço das salas de aulas, trabalhando apenas com o material disponível naquele lugar e naquele instante. Agora eles podem interagir e desenvolver o conhecimento, sendo instigados a procurar a informação, a qualquer tempo ou local por meio online.

\subsection{AMBIENTE VIRTUAL DE APRENDIZAGEM COMO SALA DE AULA ONLINE}

As instituições de ensino que ministram cursos a distância precisam moldar um ambiente que seja possível a transmissão do conhecimento bem como o monitoramento dos alunos por meio da internet da melhor forma possível, já que a falta de contato face a face causa um distanciamento da relação aluno e instituição. Normalmente esses ambientes online recebem o nome de Ambientes Virtuais de

Disponível em: https://www.nucleodoconhecimento.com.br/educacao/desenvolvimento-da- 
Aprendizagem (AVA) ou Learning Management System (LMS) e funcionam partir de um software que pode ser livre ou privado.

Teles (2009) afirma que com a EaD o conceito de ensino muda totalmente, uma vez que não existem mais salas de aulas com carteiras dispostas todas voltadas para frente e um quadro-negro preso na parede. Com essa modalidade de ensino o acesso a educação pode ser feito de qualquer lugar do mundo a qualquer hora que o aluno deseje.

Um Ambiente Virtual de Aprendizagem é um software (programa) que permite o gerenciamento de cursos on-line. Esses ambientes permitem o gerenciamento de cursos on-line por meio de um conjunto amplo de recursos que incluem desde a publicação e disponibilização de conteúdos, ferramentas de comunicação síncrona e assíncrona, construção de textos colaborativos e ferramentas de avaliação. Permitem ainda o acompanhamento das atividades desenvolvidas pelos alunos durante o curso por meio de relatórios que apontam o número de acessos, recursos acessados pelos alunos e seu boletim de notas (LAZILHA, 2011, p. 14).

De acordo com Munhoz (2011) os diversos ambientes virtuais de aprendizagem recebem diferentes nomenclaturas. No Brasil a nomenclatura AVA é a mais encontrada na literatura, porém também podemos encontrar o termo LMS, referindose a abreviação do nome em inglês, mas independente do nome usado, esses sistemas utilizam diversos programas com tecnologia suficiente para tornar possível a troca de informações e materiais.

Dentro do Ambiente Virtual de Aprendizagem temos diversas ferramentas que ajudam na prática pedagógica do aluno, e estas devem ser moldadas conforme os objetivos de cada instituição. Desta forma Moore e Kearsley (2008) afirmam que, associado ao sistema de desenvolvimento e transmissão de cursos com base na web, as instituições utilizam Sistemas de gerenciamento do aprendizado (LMS) para gerenciar as informações e registros dos alunos além de integrar as atividades síncronas e assíncronas em uma sala de aula online. Para auxiliar os profissionais na gestão do AVA existem ainda ferramentas de autoria que são programas de computadores, desenvolvidos para serem usados por não-programadores a fim de criar treinamentos,

Disponível em: https://www.nucleodoconhecimento.com.br/educacao/desenvolvimento-da- 
apresentações interativas e multimídias de forma mais simples, de modo que o programa traduz os comandos para um código de programação utilizado pelo computador e dispositivos de hardware.

Muitas vezes o conceito de tecnologia é confundido com mídias, desta forma, segundo Moore e Kearsley (2007, p.7) "a tecnologia é que constitui o veículo para comunicar mensagens e estas são representadas em uma mídia". Ainda de acordo com o autor temos quatro tipos de mídias, textos, imagens, sons e dispositivos.

Para melhor descrever, segue abaixo um quadro explicativo com as principais ferramentas tecnológicas utilizadas na Educação a distância:

Quadro 01: Principais ferramentas tecnológicas utilizadas na Educação a distância.

\begin{tabular}{|c|c|c|}
\hline FERRAMENTA & DESCRIÇÃO & COMUNICAÇÃO \\
\hline E-mail & $\begin{array}{l}\text { Envio de correspondências em textos ou } \\
\text { com arquivos anexados. Ajudou a diminuir } \\
\text { os custos e aumentou a velocidade de } \\
\text { transmissão da informação. Engloba todos } \\
\text { os envolvidos com o curso ou } \\
\text { administração do AVA e é considerado um } \\
\text { dos principais meios de comunicação em } \\
\text { EAD. }\end{array}$ & Assíncrona \\
\hline Fórum & $\begin{array}{l}\text { Quadro de mensagens que dispõe de } \\
\text { temas para debate. Pode ser organizado } \\
\text { por ordem cronológica ou por mensagem. } \\
\text { Deve-se tomar cuidado para o aluno não } \\
\text { ter medo de expor suas ideias. }\end{array}$ & Assíncrona \\
\hline Chat & $\begin{array}{l}\text { Estabelece discussões por via textual, } \\
\text { enviando e recebendo mensagens, } \\
\text { estabelecendo conversação em grupos ou } \\
\text { em particular. O professor deve mediar o }\end{array}$ & Síncrona \\
\hline
\end{tabular}

Disponível em: https://www.nucleodoconhecimento.com.br/educacao/desenvolvimento-daeducacao 


\begin{tabular}{|c|c|c|}
\hline & $\begin{array}{l}\text { chat para que o assunto não se desvie. É } \\
\text { possível disponibilizar o chat para que os } \\
\text { alunos que não participaram possam ver o } \\
\text { que foi discutido. }\end{array}$ & \\
\hline $\begin{array}{l}\text { Listas } \\
\text { Discussão }\end{array}$ & $\begin{array}{l}\text { Permitem o envio de correspondências } \\
\text { eletrônicas para um grupo de endereços } \\
\text { previamente cadastrados em um servidor } \\
\text { de listas. Permite a moderação do } \\
\text { conteúdo que é repassado. }\end{array}$ & Assíncrona \\
\hline Realidade Virtual & $\begin{array}{l}\text { Permite simular um ambiente real ou } \\
\text { imaginário em três dimensões. Pode } \\
\text { fornecer sensações por meio de } \\
\text { movimentos naturais e tridimensionais do } \\
\text { corpo. Exige grande largura de banda da } \\
\text { internet. }\end{array}$ & Síncrona \\
\hline Audioconferência & $\begin{array}{l}\text { Permite dois ou mais alunos se } \\
\text { conectarem via linha telefônica ou } \\
\text { equipamentos desenvolvidos para } \\
\text { conectar as linhas. }\end{array}$ & Síncrona \\
\hline Audiográfico & $\begin{array}{l}\text { Espécie de quadro-negro, porém virtual } \\
\text { para a transmissão do conhecimento e } \\
\text { também a utilização de áudio. }\end{array}$ & Síncrona \\
\hline Videoconferência & $\begin{array}{l}\text { Permite aos participantes manterem, em } \\
\text { dois ou mais locais, uma comunicação } \\
\text { mediante uso de equipamentos eletrônicos } \\
\text { compartilhando espaços acústicos e } \\
\text { visuais como se estivessem no mesmo } \\
\text { local. É a única que permite explorar a } \\
\text { linguagem corporal com imagem e som em } \\
\text { tempo real. }\end{array}$ & Síncrona \\
\hline
\end{tabular}

Disponível em: https://www.nucleodoconhecimento.com.br/educacao/desenvolvimento-daeducacao 
Fonte: BRITO, Mário Sérgio da Silva. Tecnologias para EAD via internet. In: NOVA, Cristiane; ALVES, Lynn (org). Educação e Tecnologia: trilhando caminhos. Salvador: Editora da UNEB, 2003. (Adaptado pelo autor).

Conforme Brito (2003) existem várias ferramentas tecnológicas disponíveis de forma síncrona ou assíncrona para a $\mathrm{EaD}$, dependendo do tipo de atividade que pretende desenvolver e da maneira que os alunos devem se comunicar as instituições podem combiná-las para alcançar seus objetivos na aprendizagem.

Dentre as diversas ferramentas tecnológicas, a videoconferência é uma das mais importantes, uma vez que possibilita a interação dos alunos e professores mais próximos do ensino tradicional no qual já estão acostumados a trabalhar, formando grupos que podem debater de forma síncrona o assunto, além disso, é uma ferramenta que pode ser transmitida via internet ou satélite (MOORE; KEARSLEY, 2003).

É por meio do AVA que o aluno mantém contato com a instituição, dentro deste ambiente ele realiza atividades, assiste às aulas, verifica suas notas, faz solicitação para a secretaria, etc. Como este ambiente faz parte do cotidiano acadêmico do aluno, as instituições precisam usar plataformas que melhor se adaptam com os objetivos que ela busca atingir.

Litto (2009) e Lazilha (2011) afirmam que os sistemas AVA podem ser gratuitos ou pagos e que as instituições devem escolhê-los de acordo com a sua necessidade, contudo, geralmente, os sistemas gratuitos são os mais populares, não apenas pela parte financeira, mas também porque as instituições podem molda-los da forma com que desejam, uma vez que possuem o código-fonte aberto, sendo que o Moodle é a plataforma mais utilizada mundialmente.

Para ilustrar melhor os principais tipos de plataformas AVA e suas características, segue o quadro abaixo para comparação: 
Quadro 02: Tipos de Plataformas AVA.

\begin{tabular}{|c|c|}
\hline AVA & PAIS CARACTERISTICAS \\
\hline & $\begin{array}{l}\text { Um dos ambientes mais populares utilizados no Brasil e no mundo. } \\
\text { Possui código fonte aberto e as instituições podem utilizá-lo } \\
\text { livremente, desde que disponibilizem a fonte para outras pessoas. } \\
\text { Utiliza linguagem de programação PHP. Neste ambiente não há um } \\
\text { limite de usuários cadastrados e um mesmo usuário pode ter mais de } \\
\text { um perfil. Não há limite de cursos e atividades cadastradas. Layout } \\
\text { de todo o ambiente pode ser customizado inclusive seus ícones. }\end{array}$ \\
\hline rd & $\begin{array}{l}\text { Sistema proprietário de código fechado. Pertence à empresa } \\
\text { Blackboard Incorporation e foi criado em } 1997 \text {. Atende } 72 \% \text { das } 200 \\
\text { maiores universidades do mundo. Possui ferramentas flexíveis, } \\
\text { gerenciamento de conteúdo, envolvimento dos alunos e avaliação } \\
\text { dos resultados. A empresa proprietária ajuda a gerenciar mudanças } \\
\text { e incrementos. Diversas ferramentas para estudantes, educadores, } \\
\text { profissionais de TI e líderes acadêmicos. }\end{array}$ \\
\hline Tel & $\begin{array}{l}\text { Software livre desenvolvido por pesquisadores do Núcleo de } \\
\text { Informática Aplicada (Nied) da Unicamp. Utilizado principalmente no } \\
\text { Brasil, com apenas uma instituição estrangeira utilizando-o. É } \\
\text { possível a criação, participação e administração de cursos. } \\
\text { Ferramentas projetadas de acordo com a necessidade. Fácil } \\
\text { manuseio, inclusive pessoas não especialistas em computação, } \\
\text { tendo um conjunto enxuto de funções. Possibilita a disponibilização } \\
\text { ao aluno de diversas ferramentas. }\end{array}$ \\
\hline Claroline & $\begin{array}{l}\text { Desenvolvido na Bélgica, pela Universidade Católica de Louvan no } \\
\text { ano de 2000, este sistema é livre. Disponibiliza recursos e } \\
\text { ferramentas mais comuns com interface amigável. Seu } \\
\text { funcionamento não requer conhecimentos técnicos avançados. } \\
\text { Plataforma presente em mais de } 100 \text { países. }\end{array}$ \\
\hline
\end{tabular}

Disponível em: https://www.nucleodoconhecimento.com.br/educacao/desenvolvimento-da- 
Dokeos Foi desenvolvido a partir do software Claroline e também é gratuito. Permite ao professor criar conteúdos pedagógicos, estruturados em rotas de aprendizagem, permitindo a interação entre os alunos. Interface muito simples para o usuário.

WebAula É um sistema nacional de código fechado que disponibiliza as principais ferramentas e recursos dos outros sistemas do mercado.

Fonte: LAZILHA, Fabrício Ricardo. Ambiente de Aprendizagem em EAD. Maringá: Cesumar, 2011. (Adaptado pelo autor)

Os principais Ambientes Virtuais de Aprendizagem utilizados atualmente são o Moodle e o Blackboard, sendo que o primeiro é o líder dos softwares com código-fonte livre e o segundo o líder dentre os softwares de código-fonte fechado. Segundo Davis, Carmean e Wagner (2009) 20,1\% das instituições de ensino e corporativas do mundo utilizam o Moodle como plataforma, contra $13,1 \%$ das organizações e instituições que usam o sistema Blackboard.

Feldstein (2010) afirma que nos Estados Unidos a plataforma Blackboard tinha a liderança absoluta do mercado de software AVA, contudo essa realidade vem se alterando a cada ano com a migração de diversas organizações para outros sistemas, sobretudo aos de código-fonte aberto, a Blackboard vem perdendo mercado, sobretudo pela redução dos custos por parte das instituições.

É evidente como sempre está ocorrendo transformações na educação a distância, onde instituições buscam novos meios de melhorar a relação de aprendizado e há uma forte tendência das instituições que utilizam sistemas privados como o Blackboard se moldarem para utilizar sistemas gratuitos, principalmente o Moodle, que aparentemente, vem atendendo muito bem aquelas que a utilizam.

Segundo Warschauer (1997, apud Teles, 2009, p. 73) os AVA's possuem muito potencial pedagógico já que se torna possível a interação grupo a grupo e não mais só de um a um. Outro fator importante que os ambientes virtuais de aprendizado

Disponível em: https://www.nucleodoconhecimento.com.br/educacao/desenvolvimento-daeducacao 
permitiram foi a independência de lugar e tempo, uma vez que é possível se conectar de qualquer lugar que possua acesso a internet, a qualquer hora.

Desde o início da EaD as tecnologias vêm contribuindo para a melhoria no processo de ensino. Com o seu avanço é possível que tenhamos uma estrutura de ensino diferente da tradicional, separando fisicamente a troca de conhecimento. Para isso as instituições devem saber ajustar os seus sistemas a fim de manter a máxima aproximação com os seus alunos para atingir seus objetivos.

\section{TENDÊNCIAS DA EDUCAÇÃO A DISTÂNCIA NO BRASIL}

É aparente como a educação a distância está se expandindo, ganhando espaço entre as pessoas e deixando de ser um mero complemento da educação presencial. Ela é outra modalidade de ensino diferente do que conhecemos e com um grande potencial a ser explorado.

De acordo com Moran (2007) apud Guarizi e Matos (2009 p. 39):

Apesar do preconceito ainda existente, hoje há muito mais compreensão que a EAD é fundamental para o País. [...]. O crescimento exponencial dos últimos anos é um indicador sólido de que a EAD é mais aceita do que antes. Mas ainda é vista como um caminho para ações de impacto ou supletivo. É vista como uma forma de atingir quem está no interior, quem tem poucos recursos econômicos, quem não pode frequentar uma instituição presencial ou para atingir rapidamente metas de grande impacto [...].

Conforme Maia e Mattar (2007) nos dias atuais muitos países independentemente da sua condição social atendem milhares de pessoas através da educação a distância, ofertando diferentes tipos de cursos nos mais diferentes graus de instrução.

Não podemos negar que nos últimos anos ouvimos cada vez mais falarmos de ensino a distância, e isso tenderá a se tornar cada vez mais comum, pois a facilidade do acesso a tecnologia e a necessidade de muitas pessoas em adquirirem conhecimentos nas mais diferentes áreas, fará com que cada vez mais essa modalidade de ensino seja procurada. Kipnis (2009) afirma que o acesso a educação

Disponível em: https://www.nucleodoconhecimento.com.br/educacao/desenvolvimento-da- 
a distância no Brasil cresceu 571 por cento entre os anos de 2003 e 2006 de acordo com o senso da educação superior realizado no ano de 2006.

No mesmo sentido Deitel, Deitel e Steinbuhler (2004) dizem que a educação a distância associada ao uso do e-learning possui chances de crescimento muito grandes, com previsão de dobrar de tamanho a cada dois anos. Contudo esse crescimento dependerá do avanço da tecnologia como a banda larga e recursos multimídia.

Mesmo com todos esses índices não podemos esquecer que para o aprendizado ser pleno na EAD é necessário que as pessoas saibam trabalhar com a tecnologia, ou seja, é preciso eliminar a exclusão digital, pois, por mais que a pessoa saiba trabalhar com os recursos disponíveis, ela necessita saber todo o potencial que pode obter deles, caso contrário o ensino não conseguirá eliminar a exclusão social e uma forma de educação muito promissora pode acabar fracassando por falta de preparo.

A formação em serviço de pessoas sem tempo ou oportunidades de retornarem aos estudos deixa de ser um sonho de muitos educadores para tornar-se realidade com a evolução tecnológica. Mas ainda se observa que o grave processo de exclusão social é aumentado com a soma do processo de exclusão digital, que atinge uma grande parcela da população dos países em desenvolvimento (MUNHOZ, 2011, p. 198).

Segundo Santos (2006, p. 117 apud Bertoncello, 2011, p. 14) podemos entender como inclusão digital o "acesso dos cidadãos às tecnologias digitais, em condições favoráveis de apropriação do seu potencial, para o desenvolvimento pessoal e coletivo". Não basta saber fazer o uso dos computadores, por exemplo, é necessário que as pessoas estejam preparadas para utilizarem essa tecnologia para usufruir dos seus recursos de maneira plena.

As pessoas precisam entender que a $\mathrm{EaD}$ não é um complemento do ensino presencial e sim outra modalidade de ensino com as suas individualidades, com novos paradigmas que estão em constante evolução. Maia e Mattar (2007, p. 69) afirmam que "a tecnologia já existe; falta saber o que fazer com ela para se produzir algo novo

Disponível em: https://www.nucleodoconhecimento.com.br/educacao/desenvolvimento-da- 
na educação, pois, até agora, o que tem sido desenvolvido é uma cópia malfeita do modelo de ensino presencial; por isso, ainda não vingou".

Bertoncello (2011) aponta alguns cuidados que devemos tomar quanto ao uso das tecnologias educacionais, pois, como já foi mencionado, o modelo não deve ser fechado, as tecnologias devem ajustar-se de acordo com os diferentes contextos em que serão utilizadas. Portanto os docentes precisam pensar sobre a correta utilização das tecnologias, elaborar projetos para descobrir a forma que elas contribuirão para a prática pedagógica e quais os objetivos esperados de acordo com a estratégia estabelecida.

De acordo com Sander (1997) para que essa modalidade de ensino cresça é indispensável que os professores saibam trabalhar com os alunos, conhecê-los, estreitando relações, como no ensino presencial, em que o professor sabe o que seus alunos estão sentindo ao assistirem a aula. O professor do EAD precisa saber usar a tecnologia a seu favor e entender o que os alunos sentem ao ter o contato com o conhecimento mediado a distância.

O ensino a distância é um processo centrado no aluno por isso é muito importante os educadores conhecerem os princípios socioculturais dos estudantes, bem como suas experiências e conhecimentos, demandas e expectativas e usar corretamente a tecnologia disponível a fim de compensar a separação física existente e criar condições de aprendizagem (BELLONI, 2006).

O preparo tecnológico dos envolvidos no processo da aprendizagem a distância é muito importante para garantir que as informações cheguem claramente de uma parte para a outra, porém não podemos esquecer que a tecnologia é apenas uma via, assim como no ensino presencial a instituição deve possuir uma boa estrutura, o preparo docente do professor continua sendo importante, afinal ele precisa ser mediador do conhecimento.

Segundo Maia e Mattar (2007) para que a educação a distância cresça é necessário que as pessoas entendam essa modalidade de ensino como uma nova forma de

Disponível em: https://www.nucleodoconhecimento.com.br/educacao/desenvolvimento-da- 
ensinar, e o primeiro passo é saber trabalhar com a tecnologia, passando por treinamentos adequados. A educação a distância evolui muito rapidamente, pois a tecnologia está em constante desenvolvimento. $O$ estudo independente e o aprendizado aberto e flexível já tornou realidade em muitas instituições e tenderá a se popularizar para as demais, tornando cada vez mais evidente a o aprendizado ao longo da vida.

Aprender ao longo da vida não é estar atento apenas no momento em que está dentro da sala de aula, seja ela física ou virtual, é estar constantemente aberto a aprender e não parar nunca, todos nós aprendemos até na terceira idade. O conhecimento contribuiu para a melhora da vida de qualquer pessoa, seja no meio acadêmico ou no mercado de trabalho, e se destacará aquele que saber mais.

Belloni (2006) descreve que a formação ao longo da vida é muito importante e crucial para a competitividade do individuo no mercado de trabalho e deve ser uma obrigação do da sociedade e do Estado, pois o mundo está em constante mudança e todos deveram acompanhá-las. Esse modelo de aprendizagem será o melhor, ou até mesmo, a única maneira de se evitar a exclusão social.

Maia e Mattar (2007) colocam que as instituições deverão saber aproveitar o que há de bom no ensino presencial e no ensino a distância, criando oportunidades de aprendizado sem fronteiras ou limitações do espaço e de tempo. Quando se trata de educação, seja ela a distância ou presencial, devemos sempre pensar no futuro, caso contrário estaremos prejudicando a nós mesmos.

O conhecimento é a chave do sucesso e eliminação das desigualdades sociais, por isso escolher a forma de disseminá-lo é muito importante, seja presencial ou a distância, e como a tecnologia está em constante aperfeiçoamento podemos esperar que daqui a alguns anos surjam novas formas de transmissão desse conhecimento, diminuindo a exclusão social.

A tecnologia é hoje tão ou mais importante para o conhecimento como era a palavra impressa quando surgiu o livro. [...] No entanto nem os

Disponível em: https://www.nucleodoconhecimento.com.br/educacao/desenvolvimento-da- 
livros nem as máquinas constroem o conhecimento e o desenvolvimento social. Ambos são obras do ser humano, que hoje encontra na nova tecnologia da informação um novo instrumento de extenso efeito multiplicador (SANDER, 2007, p. 20).

A educação a distância é uma ótima alternativa para levar o conhecimento a diversas pessoas, em diferentes lugares do mundo simultaneamente e está indo para o caminho certo, que é aperfeiçoar-se a cada dia e aos poucos essa modalidade de ensino vai incorporando novas tecnologias, ganhando o reconhecimento das pessoas, instituições e do Estado.

Para ilustrar melhor as tendências da educação a distância no Brasil, foi consultado o Anuário ABRAEAD 2005, o CensoEaD 2008 e o CensoEad 2011, desenvolvidos pela Associação Brasileira de Educação a Distância (ABED), destacando o período de três anos entre os documentos.

Sobre as mídias utilizadas por essas instituições para ministrar os cursos, no primeiro documento analisado referente ao ano de 2004 temos recursos impressos, e-learning, televisão, vídeo, rádio, CD-Rom, entre outros não citados. No relatório de 2008 já apareceram, além das citadas anteriormente, novas mídias utilizadas pelas instituições, como por exemplo, o satélite, DVD, teleconferência, videoconferência e telefone celular. No relatório mais recente publicado em 2011 são listados vários novos recursos como whiteboard (lousa eletrônica), animações, simulações, redessociais e webconferências. Desta forma fica claro que as tecnologias de informação e comunicação estão sendo amplamente utilizadas nesta modalidade de ensino, agregando mais recursos e melhorando o ambiente e comunicação.

Outra pesquisa recente foi realizada em fevereiro de 2013 pelo site Learning \& Performance (LEARNING e PERFORMANCE BRASIL, 2003) onde aponta que quase metade das organizações preferem comprar um sistema LMS ao invés de criar um sistema próprio. A maioria das organizações implementaram o sistema para centralizar e gerenciar as atividades de aprendizagem e mais da metade das organizações que responderam a pesquisa estão satisfeitas com a integração deste sistema e continuarão com a plataforma.

Disponível em: https://www.nucleodoconhecimento.com.br/educacao/desenvolvimento-da- 


\section{CONSIDERAÇÕES FINAIS}

Com esta pesquisa é possível identificar o inicio da educação a distância no mundo e no Brasil, os recursos tecnológicos envolvidos nessa modalidade de ensino e quais as tendências dessa nova forma de transmitir o conhecimento.

Com o uso das tecnologias para a educação, vem criando-se novos paradigmas e surgindo novas possibilidades de expansão e acesso ao conhecimento. Com as ferramentas assíncronas, como o e-mail e os fóruns de discussão, alunos e professores não precisam mais compartilhar o mesmo espaço físico e de tempo para interagirem, contudo, atualmente, a principal ferramenta tecnológica que se destaca pela proximidade com o ensino tradicional é a videoconferência, pois é possível trabalhar com interpretações de expressões corporais muito melhor que outras ferramentas, além disso, traz uma maior interação entre alunos e professores, diminuindo a sensação de exclusão que é presente no ensino a distância.

Utilizando-se de conceitos de LMS as instituições conseguem criar sistemas de gestão para disponibilizar materiais de estudo e monitorar os alunos conforme a sua necessidade. Temos o desenvolvimento de diversas plataformas, contudo a plataforma Moodle é tida como um dos principais sistemas LMS, pois por ele ser de código aberto, permite esse trabalho de moldar o ambiente conforme a instituição deseja, além de ser gratuito. Em segundo lugar fica o sistema Blackboard.

A todo o momento a tecnologia vem se desenvolvendo e, como cada vez mais a educação esta atrelada a meios tecnológicos para transmitir o conhecimento, ela se desenvolve junto, afirmando as tendências de expansão da EaD por meio dos censos realizados. A internet possui muito potencial sobre essa modalidade de ensino, tanto no que diz respeito ao aumento do número de estudantes matriculados, que ajuda levar a educação em lugares onde com o ensino presencial era difícil, como na melhoria dos recursos disponíveis para transmissão do conhecimento e monitoramento da aprendizagem, pois a cada censo vemos um expressivo aumento da diversidade de recursos disponíveis para as instituições, assim é muito importante 
que as pessoas entendam e aceite esse novo conceito de educação, pois ele faz parte do presente e, sobretudo, do futuro.

\section{REFERÊNCIAS}

ALVES, João Roberto Moreira. A história da EAD no Brasil. In: LITTO, Frederic. Michael; FORMIGA, Manuel Marcos Maciel (org). Educação a distância: o estado da arte. São Paulo: Pearson Education do Brasil, 2009. p.9-13.

ASSOCIAÇÃO BRASILEIRA DE EDUCAÇÃO A DISTÂNCIA. Censo ead br. São Paulo: Pearson Education do Brasil, 2010.

ASSOCIAÇÃO BRASILEIRA DE EDUCAÇÃO A DISTÂNCIA. Censo ead br: relatório analítico da aprendizagem a distância no Brasil. São Paulo: Pearson Education do Brasil, 2012.

BELLONI, Maria Luiza. Educação a distância. 4. ed. Campinas: Autores Associados, 2006.

BERTONCELLO, Ludhiana. Novas tecnologias de informação e comunicação na educação contemporânea. Maringá: Cesumar, 2011.

BRITO, Mário Sérgio da Silva. Tecnologias para EAD via internet. In: NOVA, Cristiane; ALVES, Lynn (org). Educação e Tecnologia: trilhando caminhos. Salvador: Editora da UNEB, 2003.

DAVIS, Beth; CARMEAN, Colleen; WAGNER, Ellen. Moodle moves to the front of the LMS adoption pack. Disponível em: < http://www.learningsolutionsmag.com/articles/111/moodle-moves-to-the-front-of-theIms-adoption-pack>. Acesso em: 07 jun. 2020.

DEITEL, H. M; DEITEL, P. J; STEINBUHLER, K. E-business e e-commerce para administradores. São Paulo: Pearson Education do Brasil, 2004. 
FELDSTEIN, Michael. The evolving LMS market, part I. Disponível em: < http://mfeldstein.com/the-evolving-Ims-market-part-i/>. Acesso em: 07 jun. 2020.

GUAREZI, Rita de Cássia Menegaz; MATOS, Márcia Maria. Educação a distância sem segredos. Curitiba: Ibpex, 2009.

KIPNIS, Bernardo. Educação superior a distância no Brasil: tendências e perspectivas. In: LITTO, Frederic. Michael; FORMIGA, Manuel Marcos Maciel (org). Educação a distância: o estado da arte. São Paulo: Pearson Education do Brasil, 2009. p.209214.

LAZILHA, Fabrício Ricardo. Ambiente de Aprendizagem em EAD. Maringá: Cesumar, 2011.

LEARNING \& PERFORMANCE BRASIL. A utilização do LMS nas organizações brasileiras. Disponível em:

http://www.elearningbrasil.com.br/pesquisa/resultados/pesq_result_132.asp>. Acesso em: 10 jun 2020.

LITTO, Frederic Michael. O atual cenário internacional da EAD. In: LITTO, Frederic. Michael; FORMIGA, Manuel Marcos Maciel (org). Educação a distância: o estado da arte. São Paulo: Pearson Education do Brasil, 2009. p.14-20.

LOPES, Luís Fernando; FARIA, Adriano Antônio. O que e o quem da EaD: história e fundamentos. Curitiba: Ibpex, 2013.

MAIA, Carmen. Guia brasileiro de educação a distância. São Paulo: Esfera, 2002. MAIA, Carmen; MATTAR, João. ABC da EAD: a educação a distância hoje. São Paulo: Prentice Hall, 2007.

MARTINS, Onilza Borges. Fundamentos da educação a distância. Curitiba: Ibpex, 2005. 
MATTAR, João. Interatividade e aprendizagem. In: LITTO, Frederic. Michael; FORMIGA, Manuel Marcos Maciel (org). Educação a distância: o estado da arte. São Paulo: Pearson Education do Brasil, 2009. p.112-120.

MOORE, Michael; KEARSLEY, Greg. Educação a distância: uma visão integrada. São Paulo: Cengage Learning, 2007.

Michael; KEARSLEY, Greg. Educação a distância: uma visão integrada. São Paulo: Cengage Learning, 2008.

MUNHOZ, Antonio Siemsen. O estudo em ambiente virtual de aprendizagem: um guia prático. Curitiba, Ibpex, 2011.

NUNES, Ivônio Barros. A história da EAD no Mundo. In: LITTO, Frederic. Michael; FORMIGA, Manuel Marcos Maciel (org). Educação a distância: o estado da arte. São Paulo: Pearson Education do Brasil, 2009. p.2-8.

PENTERICH, Eduardo. Ambientes Virtuais de Aprendizagem. In: VIGNERON, Jacques; OLIVEIRA, Vera Barros de. (org.) Sala de aula e tecnologias. São Paulo: Instituto Metodista de Ensino Superior, 2009.

PETERS, Otto. A educação a distância em transição. São Leopoldo: Unisinos, 2003.

ROSENBERG, Marc J. E-learning. São Paulo: Pearson Education do Brasil, 2002.

SANCHEZ, Fábio. Anuário brasileiro de educação aberta e a distância, 2005. São Paulo: Instituto Monitor, 2005.

TELES, L. A aprendizagem por E-learning. In: LITTO, Frederic. Michael; FORMIGA, Manuel Marcos Maciel (org). Educação a distância: o estado da arte. São Paulo: Pearson Education do Brasil, 2009. p.72-80. 
SANDER, Benno. Perspectivas da educação a distância na América Latina. In: Perspectivas da educação a distância: América Latina, Seminário de Brasilia, 1997. Brasilia: Ministério da Educação e do Desporto, 1998.

Enviado: Julho, 2020.

Aprovado: Dezembro, 2020. 